\title{
ZüLFE, Ömer (Hazırlayan): Hecrî Kara Çelebî Muhyi'd-dîn Mehmed Dîvān (İnceleme-Metin-Çeviri-Dizin): Ankara 2016. Türk Dil Kurumu Yayınları.
}

Nihal DEMIR*

\begin{abstract}
Öz
Ömer Zülfe tarafından hazırlanan Hecrí Dívān'ının tanıtımını yaptığımız bu yazıda öncelikle çalışmanın ana hatlarına değinilmiş daha sonra çalışmada yazarının görüşünden ayrıldığım bazı noktalara dikkat çekilmiştir. Bu yolla çalışmaya katkıda bulunmuştur.
\end{abstract}

Anahtar Kelimeler: Beyit, Dívān, Hecrí.

\begin{abstract}
The Hecrî prepared by Ömer Zülfe this paper is primarily addressed to the outline of the work I was working then separated from the opinions of the authors drawn attention to some points that we're promoting Dîvân. This way contributed to the work.
\end{abstract}

Keywords: couplet, Dîvân, Hecrî.

Çalışmaya konu olan Hecrí mahlaslı şairin adı Meḥmed, lakabı Muhyi'd-dín olup Ḳara Çelebi olarak tanınmıştır. Doğum tarihi kesin olarak bilinmeyen Hecrínin ölüm yılı 965/1557'dir. Karamanlı mı yoksa Bursalı mı olduğu da tezkireciler tarafından aydınlatılamamış bir husustur. Hecrí ve Kara Çelebi-zâdeler olarak bilinen ailesi kadılık, müderrislik, kazaskerlik, şeyhülislamlık gibi önemli vazifelerle Osmanlı Devleti'ne hizmet etmişlerdir.

Hecrí, Kemal Paşa-zâde gibi devrin önde gelen âlimlerinden aldığı eğitimle öncelikle muîd olmuş daha sonra Bursa, Kütahya, Amasya ve Edirne'de çeşitli medreselerde müderrislik yapmıştır. Şam ve Bursa kadılıklarına atanan Hecrí, bir süre sonra müderrislik vazifesine geri dönmüştür. Yeniden kadılık mesleğini icra eden Hecrí Bursa, Edirne ve İstanbul kadılıklarında bulunmuştur. İstanbul kadılığı yaptığı esnada vefat eden şairin kabri Edirnekapı'da hocası Kemal Paşa-zâde'nin kabrinin yanında bulunmaktadır.

Hecrínin kaleminin kuvvetli, şiirlerinin latifeli ve ilminin derin olduğu konusunda tüm tezkireciler hemfikirdir. Ancak Hecrí birkaç beyiti haricinde kendini övmekten çekinmiş, vakur duruşunu korumuştur. Hecrí, şiirlerini atasözleri ve deyimlerle işleyerek îrâd-ı mesel başta olmak üzere

Bilecik Şeyh Edebali Üniversitesi Sosyal Bilimler Enstitüsü, Türk Dili ve Edebiyatı Anabilim Dalı Yüksek Lisans Öğrencisi. 
kullandığı söz sanatlarıyla tekdüzelikten sıyrılarak şiirine canlılık getirmiştir.

Kelam ve fıkıh ilimlerinde derin bilgisi olduğu bilinen Hecrínin şiirlerini topladığı Dívān'ından başka bu ilimlere olan hâkimiyetini gösteren Arapça eserleri de vardır. Vāḳıaat-ı Kara Çelebí, Sefínetü'dDürer, Risāle fíl-Vakf, Gül-i Sad-Berg, Vakfet-i Kara Çelebí fıkıh, kelam ve hadis üzerine yazdığı eserlerindendir.

Zülfe çalışmasına konu olan Hecrí Dívānı'nı eserinde şu şekilde ele almıştır: "Ön Söz" (7), “Kısaltmalar” (8), “işaretler” (9), “Kaynaklar” (11-13), "Hecri/Hayatı" (15-21), "Edebî Kişiliği”" (23-38), "Metin Kurulurken Tutulan Yol” (39-40), "Divān- Hecri” (41), “Gazeller" (41-148), "Musammatlar" (149156), "Ekler" (157-158), Dizin (159-212). Son olarak sayfa numarası vermeden çalışmasının sonuna Dívān'ın tıpkıbasımını eklemiştir.

Hecri'nin hayatını "Adı ve Mahlası" (15), “Doğum Yeri ve Ailesi” (15-16), “Eğitimi ve Mesleği” (16-17), “Ölümü” (17-18), “Eserleri” (18-19), "Hayatı ve Kişiliğine Dair İzler” (1921) başlıkları altında değerlendirmiştir.

Hecrínin edebî kişiliğini ise "Kaynakların Şiirini Değerlendirişi” (23-24), “Kendi Şiirini Değerlendirişi”" (24-25), “Dil ve Üslupla IIlgili Dikkatler" (25-32), "Kullanılan Vezinler" (3234), “Atasözleri, Deyimler, Kalıp Sözler” (3538) başlıkları altında toplamıştır. "Atasözleri, Deyimler, Kalıp Sözler" başlığında Dívān'da gazel ve musammatlarda geçen atasözlerine, deyimlere ve kalıp sözlere yer verilmiştir. Ancak bazı atasözü ve deyimlerin metinde geçtiği şekliyle değil de günümüz Türkçesine aktarılmış olarak bu bölüme alınmış olması dikkat çekicidir.

“Gazeller” bölümünde yüz kırk iki gazel transkribe edilmiştir. Okuyucuya kolaylık sağlamak adına beyitlerin satır numaralarına göre aynı sayfa içerisinde dipnot olarak çevirilerine de yer verilmiştir. Gazeller numaralandırılarak Arap alfabesi esas alınarak dizilmiştir. Her gazelin başında vezinler ve ait oldukları bahirler yer almaktadır.

Musammatların da çevirileri tıpkı gazeller gibi bulunduğu sayfada dipnot olarak verilmiştir. Her musammatın başında vezinler ve ait oldukları bahirler yer almaktadır.

Çalışmanın ana hatlarından sonra çalışmada yazarının görüşünden ayrıldığım bazı hususlara değinmek isterim:

1. Atasözleri, deyimler, vecizeler, kalıp sözler döneminin dil özelliklerini, yaşam koşullarını ve toplumun hayata bakışını anlatmada önemli birer malzemedirler. Bu sebeple bunları döneminde kullanıldığı şekliyle anlamak ve o bağlamda değerlendirmek gerekir. 
Çalışmanın "2.5. Atasözleri, Deyimler, Kalıp

Sözler" (35-38. s.) bölümünde yer alan bazı atasözleri, deyim ve kalıp sözlerin metnin orijinalinde geçen şekline sadık kalınmadan günümüz Türkçesine aktarılmış biçimleriyle bu bölüme alınması zannımca uygun değildir. Örneğin:

arayan tanrısını bulur (G. 109/5)

Hâlbuki metnin orijinalinde "isteyen tanrısın bulur”. Dönemin dil özelliklerine sadık kalınarak bu atasözünün bu şekliyle bu bölüme alınması daha uygun olacaktır.

buldı hecrí isteyüp símín ŝanemlerde seni tanrısın bulur demişler çünki èy yār isteyen bıçak kemiğe dayanmak (G. 8/4)

Metnin orijinalinde "bıçak kemüge èrmek" biçiminde yer alması sebebiyle bu deyimin "Atasözleri, Deyimler, Kalıp Sözler" bölümüne bu şekliyle alınması daha uygun olacaktır.

tíg-i hicrān-ıla derdā kemüge èrdi bıçak yèter èy huūní yèter cevr ü cefā bir kerem èt
2. Dizin bölümündeki dāğ (Far. yara) maddesi içerisinde Tü. olan dag̉ (Tü. dağ) kelimesine de yer verilmiştir. dag̉ (Tü. dağ) sözcüğü için ayrı bir maddebaşı oluşturulması gerekmektedir. Örneğin;

dil zār síne tahta kara pullar oldı dāg ġam şeş-derinde umma ŝaḳın hecriyā küşād (G. 18/5)

beyitinde yer alan dāg kelimesi Far. yara anlamındadır ve bu maddebaşı içerisine alınabilir. Ancak;

def'ètdi bāde ile ġamum pír-i mey-fürūş dağ|arı akdarur dèdiler himmetü'r-ricāl beyitinde yer alan dag̉ kelimesi Tü. dağ anlamındadır ve bu kelime için ayrı bir dag maddebaşı oluşturulmalıdır.

Zülfe'nin “Dizin” bölümüne maddebaşı olarak aldığı G. 128/1'de geçen oynayavuz bu haliyle dizine girmemelidir. oyna- fiilinin 1.çokluk istek eki almış biçimiyle oluşan oynayavuz, oyna- madde bașı içerisinde verilmelidir. oynayavuz<oyna-(y)avuz.

Dizinde yer alan benzer maddebaşı da benzemaddesi içerisine alınmalıdır. G. 51/5'de geçen bu madde benze-fiilinin geniş zaman 
ekiyle çekime girmiş şeklidir. Bu yüzden ayrı bir maddebaşı yapılmamalıdır.

3. Dizin bölümüne artuğ ve yog் şeklinde alınan maddebaşlarının artuk ve yok şeklinde Dizin'e alınması gerekmektedir.

artuk ve yok kelimeleri kendisinden sonra ünlü ile başlayan bir ek aldığında ötümlüleșir. Bu sebepten beyitlerde artuğa, yog̉-iken biçimlerini almaktadır. Ancak bu kelimeler Dizin'e artuk ve yok şeklinde alınmalıdır.

\section{KISALTMALAR}

4. Dizin bölümüne alınan uyan-, uyanık, uğrın, koçal-gibi kelimeler 17. yy.a ait ses ve ses benzeşmeleri üzerine önemli bir inceleme olan Meninski'nin Thesaurus'una bakıldığında böyle okunmamalıdır. Hecrínin de 16. yy.da yaşadığı göz önüne alındığında bu kelimelerin Meninski'nin sözlüğünde belirttiği üzere sırasıyla oyan- (554. s.), oyanık (554. s.), og̉rın (554. s.), kocal- (3784. s.) şeklinde okunması ve Dizin'e de böyle alınması gerekmektedir.
Far. : : Farsça

G. : GazelS

Tü. $\quad$ : Türkiye Türkçesi

\section{KAYNAKÇA}

MeNINSKI, Franciscus á Mesgnien: Thesaurus Linguarum Orientalium TurciaeArabicae-Persicae, I-IV: (Yayımlayan: Mehmet ÖLMEZ): İstanbul 2000: Simurg. Türk Dilleri Araştırmaları Dizisi: 32.

STEINGASS, F.: A Comprehensive Persian- English Dictionary London 1892.

TAŞ, ibrahim: Yûsuf ile Zelîhâ İstanbul 2008: Türk Dilleri Araştırmaları Dizisi: 42. 